\title{
PROPOSTA DE ANTEPROJETO E IMPLANTAÇÃO DE HABITAÇÃO DE INTERESSE SOCIAL PARA O CLIMA SEMIÁRIDO
}

\author{
PROPOSAL FOR A DRAFT PROJETC AND IMPLEMENTATION OF \\ SOCIAL INTEREST HOUSING FOR THE SEMIARID CLIMATE
}

\author{
Vanderli De Araújo Gomes ${ }^{1}$ \\ Camilla Furtado de Figueiredo ${ }^{2}$ \\ Ezio Luiz Martins Simões ${ }^{3}$ \\ Emanoella Bella Sarmento Salgueiro Eliziário Matias ${ }^{4}$ \\ André Ferreira Costa ${ }^{5}$ \\ Marjorie Maria Abreu Gomes de Farias ${ }^{6}$
}

\footnotetext{
${ }^{1}$ Graduanda em Arquitetura e Urbanismo pela Faculdade Santa Maria.

${ }^{2}$ Graduada em Arquitetura e Urbanismo pela Universidade Federal da Paraíba (2014), pós-graduada Habitação Social e Direito à Cidade pela Universidade Federal da Bahia (2016), pós-graduada em Arquitetura, Gestão e Construção de Edificações Sustentáveis pela Faculdade Unyleya (2016), mestre em Engenharia de Energias Renováveis com dissertação voltada para a pesquisa de alternativas de materiais de construção sustentáveis pela Universidade Federal da Paraíba (2017). Atualmente, é docente da Faculdade Santa Maria (FSM) e no Centro Universitário de João Pessoa (UNIPE), ambos no curso de Arquitetura e Urbanismo.

${ }^{3}$ Possui graduação em Arquitetura e Urbanismo pelo Centro Universitário de João Pessoa (2012) e mestrado pela Universidade Federal da Paraíba (PPGAU-UFPB). Atualmente é professor nas Faculdades Integradas de Patos-PB (FIP), mas também já trabalhou como professor na Faculdade Santa Maria de Cajazeiras-PB (FSM). Atua principalmente nos seguintes temas: requalificação urbana, bioclimatismo, projeto participativo e arquitetura. Além das atividades profissionais, é acadêmico do curso de Engenharia Civil pela UFCG - CCTA - campus Pombal-PB.

${ }^{4}$ Pesquisadora mestra (2015) pelo Programa de Pós Graduação em Arquitetura e Urbanismo, PPGAU - UFPB. Arquiteta e Urbanista, formada pela Universidade Federal da Paraíba (2011). Colaboradora do Laboratório de Acessibilidade (LACESSE) - UFPB desde 2012 e integrante do grupo de pesquisa Qualidade, Acessibilidade, Tecnologia e Percepção do Ambiente Construído, certificado UFPB e CNPq. Coordenadora e docente do curso de Arquitetura e Urbanismo da Faculdade Santa Maria (FSM) de Cajazeiras, na Paraíba.

${ }^{5}$ Desde 2016 é professor da Faculdade Santa Maria de Cajazeiras, atuando no curso de Arquitetura e Urbanismo e no curso de Engenharia Civil. Possui graduação em Engenharia Civil pela Universidade Federal da Paraíba (2014), graduação em Construção de Edifícios pelo Instituto Federal de Educação, Ciência e Tecnologia da Paraíba (2014) e especialização em Gerenciamento de Projetos pela Fundação Getúlio Vargas (2016). Tem experiência profissional na área de Engenharia Civil, com ênfase em Gerenciamento e Execução de Obras.

${ }^{6}$ Arquiteta e Urbanista, graduada pela Universidade Federal da Paraíba (UFPB) (2013) e mestre pelo Programa de Pós-graduação em Arquitetura e Urbanismo da Universidade Federal da Paraíba (PPGAU-UFPB) (2015). Atualmente é professora do curso de Bacharelado em Arquitetura e
} 
RESUMO: As habitações sociais constituem uma solução de moradia para famílias de baixa renda, e são geralmente desenvolvidas por governos, sem que haja uma preocupação com soluções arquitetônicas visando melhorar questões como eficiência energética e conforto. Na maioria das vezes, os fundamentos básicos da boa arquitetura não são adotados nesse tipo de habitação e, desse modo, ocorre a requalificação das áreas de interesse social. Neste contexto, o trabalho propõe um projeto de habitação de interesse social, com soluções passivas e de baixo custo que venha a atender as peculiaridades do semiárido, com o propósito de melhorar a qualidade de vida dessa população, destacando ainda, as características dessa região peculiar. Para isso, foi necessário cumprir as seguintes etapas metodológicas: pesquisa analise e anteprojeto. Este trabalho obteve resultados que atenderam aos critérios técnicos de custeio, e as soluções passivas e de baixo custo adotadas foram essenciais para compor um projeto de habitação de interesse social, condizente e adaptável às condições do semiárido.

PALAVRAS CHAVE: habitação de interesse social. semiárido. projeto arquitetônico.

ABSTRACT: Social habitation is a dwelling solution for low-income families, and it is usually developed by governments, without any concern with architectural solutions aimed to improving issues such as energy efficiency and comfort. Most of the times, the basic fundamentals of good architecture are not adopted in this type of housing and, thus, there is the requalification of the areas of social interest. In this context, the project proposes a dwelling project of social interest, with passive and low-cost solutions that will meet the peculiarities of the semi-arid, with the purpose of improving the quality of life of this population, highlighting also the characteristics of this peculiar region. For such, there was need to follow such methodological steps: research, analysis, and draft. From this work, the results that followed the technical criteria for costing were obtained, and the passive and low-cost solutions adopted were essential to become part of a social dwelling, appropriate and adaptable to the semi-arid conditions.

KEYWORDS: habitation of social interest. Semi-arid. Architectural project.

Urbanismo da Faculdade Santa Maria - Cajazeiras-PB. Tem experiência ministrando aulas e trabalhando com iniciação científica nos seguintes temas: acessibilidade, mobilidade, avaliação pósocupação, sistema de espaços livres, avaliação pós-ocupação e representação e concepção de projeto. 


\section{INTRODUÇÃO}

A habitação social também conhecida como habitação de interesse social teve seu início efetivamente no Brasil a partir da era Vargas, em 1930, quando o governo passou a regular aluguéis e subsidiar a construção de moradias. Até então, as iniciativas existentes provinham da iniciativa privada, por meio da construção de moradias para trabalhadores. Atualmente, pode-se dizer que é feita geralmente pelo Poder Público e é destinada à população cujo nível de renda dificulta ou impede o acesso à moradia por meio dos mecanismos normais do mercado imobiliário.

O principal objetivo desse tipo de projeto é reduzir a falta da oferta de imóveis residenciais de baixo custo dotados de infraestrutura (redes de abastecimento d'água, esgotamento sanitário e energia elétrica) e acessibilidade. Além disso, em algumas situações, pretende fazer a realocação de moradias irregulares ou construídas em áreas de risco (BONDUKI, 1994).

Importa mencionar que se observa a falta da aplicabilidade de soluções arquitetônicas em habitações de interesse social no Brasil, os quais não têm recebido atenção devida no momento da elaboração das diretrizes de implantação dessa natureza. Na maioria das vezes, os fundamentos básicos da boa arquitetura não são adotados nesse tipo de habitação e, desse modo, ocorre a requalificação das áreas de interesse social, ainda assim, o déficit habitacional continua sendo um problema recorrente (PALERMO et al., 2007; CHEQUETTO et al., 2015).

O nordeste brasileiro tem sofrido um grande aumento na população urbana nas últimas décadas. A saída dessas famílias da zona rural para cidade, em busca de melhores condições de vida, tem aumentado de forma considerável a necessidade dessa tipologia.

Localizada em sua maior parte na região nordeste do Brasil, e com uma área de mais de 900 milhões de $\mathrm{m}^{2}$, no qual estão inseridos 1.133 municípios e mais de 20 milhões de habitantes, a região do semiárido é caracterizada pelas temperaturas elevadas, com média de $23^{\circ} \mathrm{C}$ a $27^{\circ} \mathrm{C}$, precipitação anual máxima de $800 \mathrm{~mm}$ e 
unidade relativa do ar em torno de $50 \%$, tornando seu clima, portanto, bastante quente e seco. A pouca quantidade de chuvas é insuficiente para atender a população (SILVA et al., 2010).

Por isso, esse estudo justifica-se pela necessidade de discutir e desenvolver projetos de moradias focadas especificamente nas características climáticas e populacionais da região do semiárido. Destaca-se que o tema proposto não dispõe de estudos específicos para o semiárido, por isso possui relevância acadêmica. Além do mais, torna-se importante explanar sobre o objeto de estudo em questão, porque, além de propor soluções de grande valia para a requalificação e adaptação de moradias, é possível, também, ofertar soluções para um problema social recorrente. Desse modo, é viável propor um projeto de habitação de interesse social que venha a atender as peculiaridades do semiárido, com a finalidade de melhorar a qualidade de vida dessa população.

Neste contexto, este trabalho almeja propor um anteprojeto e implantação de habitação de interesse social que venha a atender as peculiaridades do semiárido. Levando em consideração ainda, a necessidade de moradias energeticamente eficientes e que proporcionem melhor conforto térmico, podendo melhorar a qualidade de vida dessa população mediante as características dessa região peculiar.

\section{METODOLOGIA}

Este trabalho consiste em uma proposta de anteprojeto e implantação de habitação de interesse social para o clima semiárido. Esse projeto será implantado na cidade de Cajazeiras, localizada no oeste paraibano, situada na mesorregião do sertão. Segundo o Instituto Brasileiro de Geografia e Estatística (IBGE), o clima predominante é quente e seco, característico do semiárido.

Compreende-se que para qualquer elaboração de projeto e inserção de novas unidades em áreas urbanas consolidadas ou de expansão é imprescindível o estudo de viabilidade técnicas normativas e ambientais pelo proponente, a fim de minimizar 
as falhas e adotar soluções condizentes com a realidade in loco. Para propor de forma consciente o crescimento urbano, pode-se observar a imagem do entorno onde será implanta a proposta.

A Rua João Lima da Silva é a continuação da Rua Otacílio Liberato de Abreu, principal rua de acesso entre os bairros Pôr do Sol e Pio X. Com o extenso crescimento urbano, a perspectiva é que essas duas ruas se transformassem em avenida, sendo este um dos principais fatores para a construção em andamento de um conjunto habitacional que foi locado a aproximadamente 2,7 quilômetros de distância do bairro Pio X. A expectativa dessa junção é que possivelmente impulsione o crescimento dessa faixa que ficou ociosa entre os setores urbanizados.

IMAGEM 01: RUA JOÃO LIMA DA SILVA.

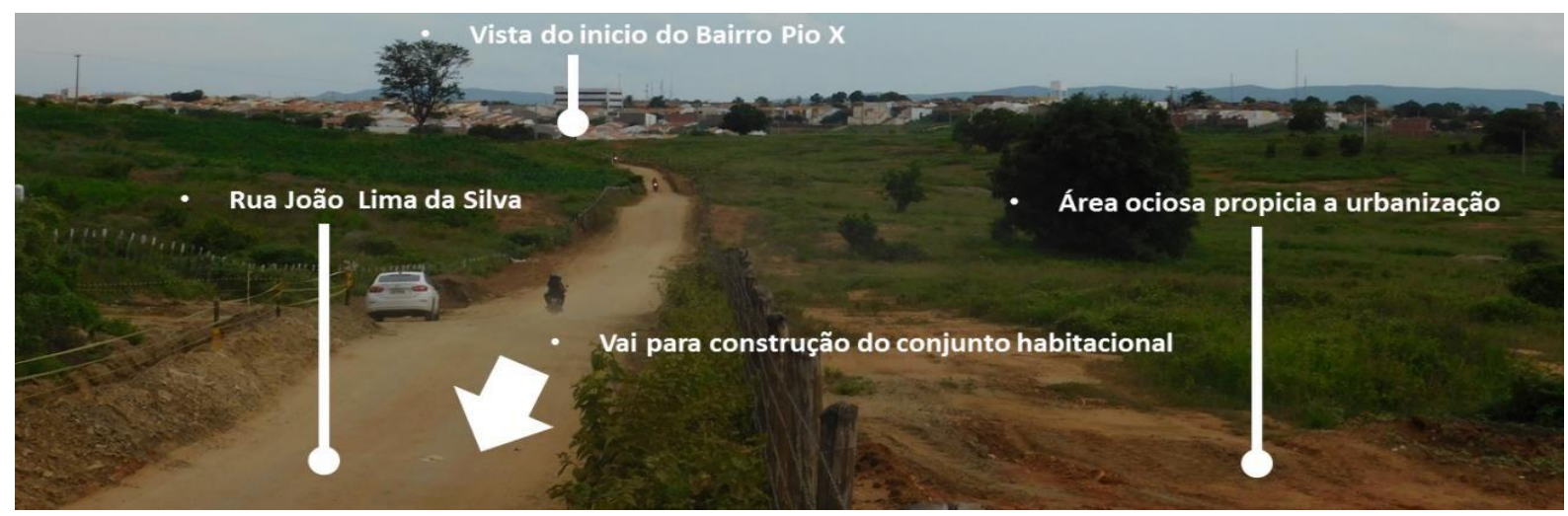

Fonte: Acervo do autor (2019).

A imagem acima retrata a situação atual dessa rua que provavelmente receberá infraestrutura necessária, pois é o único acesso entre a área já consolidada e a construção em andamento das 600 novas moradias.

Diante do exposto e munido do levantamento topográfico elaborado para essa proposta, é possível interpretar as necessidades de movimentação de terra para melhor aproveitamento da área a ser utilizada.

Após análise visual da proposta de arruamento, é possível compreender os dados por meio da tabela seguinte: 
TABELA 01: QUADRO REPRESENTATIVO DE ÁREA GERAIS REFERENTE AO MAPA DE ARRUAMENTO

\begin{tabular}{|l|l|}
\hline \multicolumn{2}{|c|}{ Quadro geral de áreas do loteamento } \\
\hline Fração correspondente & Valor $\mathrm{m}^{2}$ \\
\hline Área total loteada & $324.014,60$ \\
\hline Área institucional & $30.342,00$ \\
\hline Área verde e convivência & $50.097,00$ \\
\hline Área comercial e serviço & $35.662,30$ \\
\hline Área das quadras & $82.031,70$ \\
\hline Área das ruas & $107.950,28$ \\
\hline Área das calçadas & $26.976,32$ \\
\hline
\end{tabular}

Fonte: Acervo do autor (2019).

O fracionamento da área representada acima tem fundamentação legal de acordo com a Lei ํo 644/78, de junho de 1978, que dispõe sobre a legislação urbanística do município de Cajazeiras. A partir do amparo da legislação vigente, a proposta de implantação atende na íntegra todas as cotas de áreas: institucional, área verde, de vivência e lazer, como também propõe uma fração de terra para passeio público condizente com a normativa ABNT NBR 9050, que trata sobre a acessibilidade. Além de seguir os critérios normativos padrões, que justifica a disponibilização de uma área de $35.662,30 \mathrm{~m}^{2}$ para serem implantados em estabelecimentos comerciais e de serviços, que serão essenciais aos futuros moradores, bem como toda a área de expansão.

$\mathrm{Na}$ análise de correlato, buscou-se entender as relações e as necessidades que as pessoas têm, levando em consideração que as particularidades ambientais nem sempre são pertinentes, podendo sofrer diversas variações em todos os aspectos. Partindo desse entendimento, foi possível avaliar os pontos positivos e negativos para as diferentes realidades, e assim, enriquecer as soluções dessa proposta.

O projeto analisado foi desenvolvido pelo escritório 24.7, que ganhou o $1^{\circ}$ lugar no concurso Público Nacional de Arquitetura para Novas Tipologias de Habitação de Interesse Social Sustentáveis, que aborda a tipologia casa térreas, conforme os dados seguintes: Arquitetos: Giuliano Pelaio, Gustavo Tenca e Inácio Cardona. Local e ano: São Paulo no ano de 2010. 
A formatação da proposta conta com duas tipologias, unidades habitacionais com dois dormitórios e três dormitórios, conforme plantas baixa. Dessa forma, observa-se que são plantas semelhantes, mas que a única diferenciação é o jardim locado entre os dormitórios, que para a unidade de três dormitórios, o terceiro dormitório faz uso de parte dessa área do jardim.

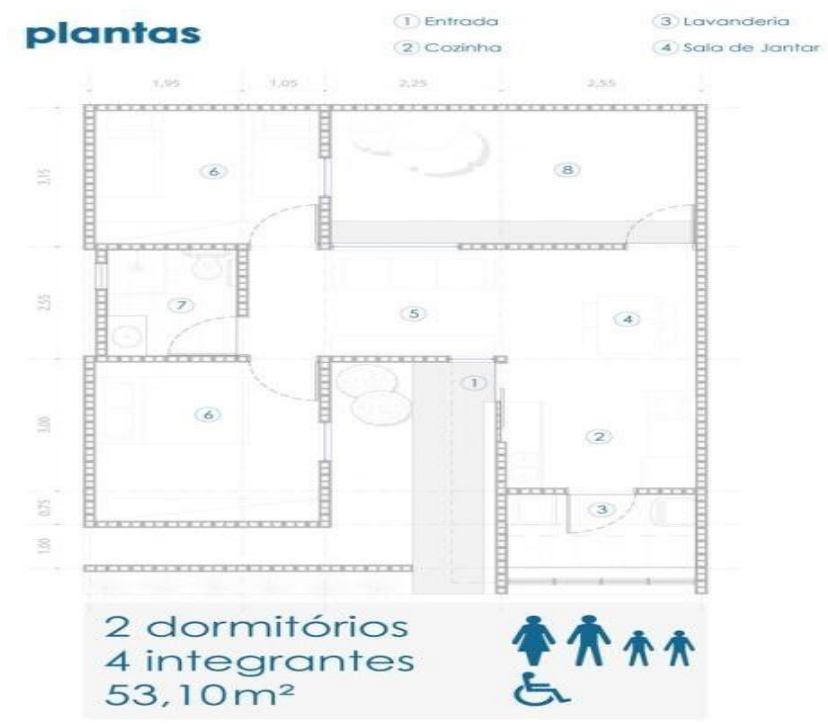

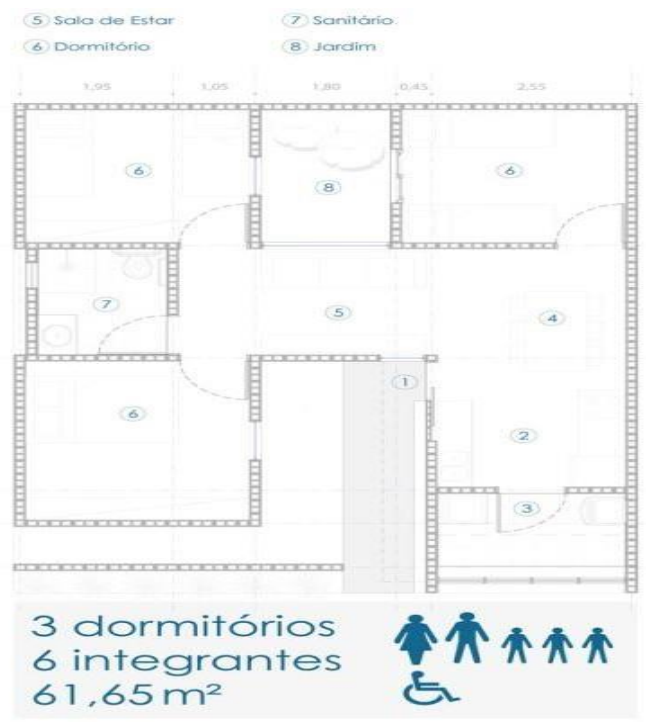

\section{IMAGEM 1}

Fonte: Escritório 24.7 (2019).

Nessa proposta, o escritório 24.7, através de seus arquitetos propõem uma nova tipologia para habitação de interesse social, que se opõe aos padrões adotados pelos governos e pelas incorporadoras, que tem produzido moradias repetidamente em todas as regiões do país de forma indiscriminada, no qual quase sempre essas unidades só dispõem de $35,00 \mathrm{~m}^{2}$. Portanto, com o propósito de demonstrar que os paramentos da formatação espacial devem atender a princípios básicos de acessibilidade, iluminação e ventilação natural, melhoramento termoacústico e sustentável, o escritório 24.7 lança uma proposta vencedora do concurso público para moradias de interesse social sustentável para cidades do estado de São Paulo.

Os aspectos construtivos diferenciam este projeto dos padrões postos pelos governos federais, estaduais e municipais. Esse projeto adota fatores qualificadores como a presença de platibanda, teto verde, volumetria, uso dos parâmetros 
utilizados no desenho universal, e o mais importante, o uso de soluções passivas para melhoramento térmico. Isso pode proporcionar iluminação e renovação do ar em todos os ambientes da edificação, levando em consideração o uso de materiais condizentes com as condições locais, sem tornar a solução adotada inviável tecnicamente e financeiramente.

O programa de necessidade segue os parâmetros exigidos pela Lei Federal no 11.124/05 - Sistema Nacional de Habitação de Interesse Social (SNHIS), que dispõe sobre a adesão dos estados e municípios na unificação dos planos habitacionais dos municípios e regiões. Nessa lei, é função do município à adaptação e as melhorias traçando-se todas as diretrizes no que consiste ao projeto implantação de acordo com características peculiares. Para essa proposta, destacase as características bioclimática dessa microrregião onde Cajazeiras-PB está inserida.

O ponto inicial para o desenvolvimento desse trabalho iniciou-se com a reflexão de todo estudo feito até a presente fase do trabalho que buscou qualificar espaços para pessoas de diferentes necessidades. Nesse casso específico, habitação de interesse social para clima semiárido, que começa com o conhecimento prévio das necessidades das pessoas e o que cada ambiente representa dentro do conjunto edificado.

Com esse entendimento, tratou-se de elaborar cada ambiente de forma única, em que cada cômodo corresponde a um quadrado ou retângulo com dimensões, funções e características distintas. Desse modo, o processo criativo tem embasamento construtivo na hierarquia intuitiva que o estudo tem direcionado. Após todos os direcionamentos de pesquisas e normativas vigentes, a construção do partido arquitetônico caminhou por linhas técnicas e não de caráter artístico, apesar de haver uma comunhão entre ambos.

É possível compreender com a análise da imagem seguinte, a ideologia da criação arquitetônica dessa proposta. A representação do partido se materializa por meio da configuração de espaços constantes em uma edificação, que pode assumir funções diversas dentro do programa de necessidades já exposto anteriormente. A formatação espacial seguiu critérios técnicos mencionados nos estudos in loco e os elementos climáticos dessa pesquisa, estão visíveis na imagem seguinte. 
IMAGEM2: PARTIDO ARQUITETÔNICO.

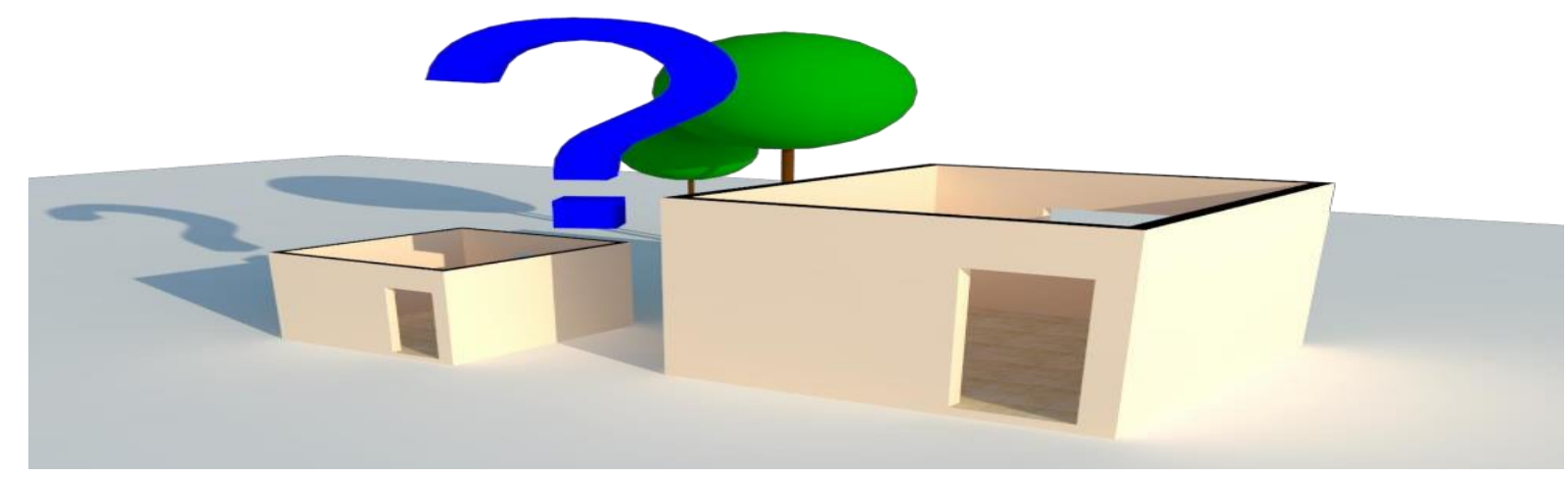

Fonte: Acervo do autor (2019).

A imagem está dividida em quatro partes que compõem a contextualização do imaginário com a materialização dos elementos arquitetônicos empregados de forma técnica. Para tanto, é preciso discorrer sobre a relação entre esses elementos.

A base branca representa o espaço destinado a implantação, o que corresponde ao terreno, elemento natural que deve ser trabalhado de forma inteligente, pois suas peculiaridades interferem no resultado das etapas seguintes.

Os volumes com aberturas semelhantes às dos ambientes de uma edificação configuram a formatação distinta que cada um assumirá após o confronto das informações e as estratégias adotadas, podendo haver um jogo de quebra cabeça até o ajuste final de sua posição no layout final. Em contrapartida, essa flexibilidade de locação individual é motivada pelas condições e fenômenos naturais como ventilação, iluminação, isolação, direcionamento das chuvas, entre outros elementos, que norteiam o caminhamento natural da criação da proposta isolada.

Vale mencionar ainda que cada ambiente tem função distinta dentro do conjunto projetado que é determinante. De acordo com a integração, os ambientes não podem ter a funcionalidade questionada, cabendo ao proponente avaliar as hierarquias de funcionalidade e bem-estar, além de primar pelo rigoroso comprimento normativo.

A interrogação representa a parte abstrata do conceito, que são os elementos que não vão ser representados graficamente, pois todo o processo criativo consiste em uma atividade mental de reflexão e conhecimentos adquiridos. Esse repertório 
está arquivado na memória, a exemplo disso é: alguém faz uma pergunta, o que é um banheiro? De imediato, será resgatado na memória o que é um banheiro.

A resposta será simples, um banheiro é um espaço constante nas edificações, geralmente na forma de um retângulo ou quadrado, equipado com aparelho sanitário, lavatório, box, chuveiros e outros acessórios a depender da tipologia da edificação. Na sequência, a interrogação surge novamente, para projetar um banheiro deve-se seguir parâmetros de medidas fornecidos por alguma normativa? Logo, à solução para o dimensionamento seria usar o código de obras da cidade onde está sendo implantado o projeto, bem como o uso da ABNT NBR 9050/2015.

Antes de concluir, tem-se mais um questionamento: onde locar o banheiro dentro do projeto? Essa resposta será dada no decorrer da construção do layout. Dessa forma, entende- se que o processo criativo depende do resgate de todo conhecimento, e que $o$ ato de projetar tem relação com a pesquisa, pois o processo mental de formalizar as ideias é o que diferencia os profissionais, já que as normas são iguais para todos.

Por fim, a representação da árvore e o sombreamento representam todas as estratégias construtivas, passivas e de baixo custo, que tendem a melhorar as condições internas dos ambientes, que podem beneficiar a qualidade de vida das pessoas ou famílias que ali habitem. 
IMAGEM 3: FLUXOGRAMA.

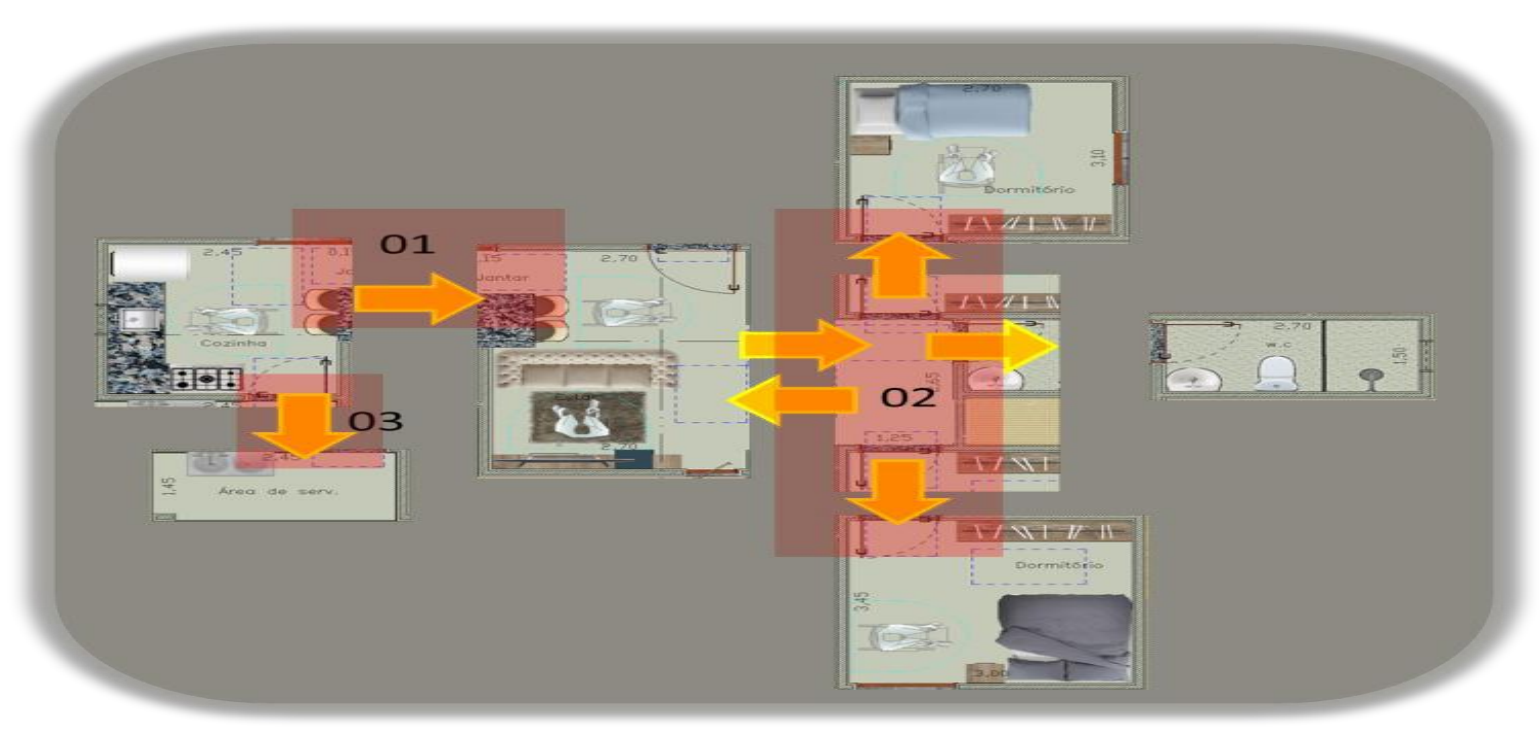

Fonte: Acervo do autor (2019)

De acordo com a tabela abaixo, é possível compreender que a relação ocupacional dos ambientes está disposta de modo que todos os ambientes dependem de uma área de uso ou de funcionalidade maior do que a área ocupada por mobílias e ocupada indiretamente pelas aberturas de portas e janelas A partir desse conceito, a relação espaço ocupado pela mobilha básica e aberturas, observa-se a concepção espacial dos ambientes que não tem sido respeitada.

A tipologia definida para essa proposta tem uma área edificada de $57,88 \mathrm{~m}^{2}$, área mínima capaz de atender os requisitos de acessibilidade recomendado pelo desenho universal e a NBR 9050/2015. Esse é um dos pontos positivos abordados nessa tipologia, pois a falta de acessibilidade tem sido um problema recorrente nos projetos que tentam atender o déficit habitacional no Brasil.

Os conjuntos habitacionais têm-se multiplicado sem que o município faça as devidas revisões em seus projetos, o que acarreta em diversas falhas, e em alguns casos, sem soluções arquitetônicas. Contudo, o estado tem cumprido o princípio constitucional de garantir moradia às pessoas que não possam ter por meios próprios. 


\section{RESULTADOS E DISCUSSÃO}

A compatibilização do norte colhido in loco com o norte fornecido pelo da rosa dos ventos fornecido pelo LabEEE proporciona o ajuste da disposição da unidade isolada. Quanto à orientação da ventilação natural nas fachadas da edificação, aproveita-se a ventilação vinda da faixa favorável no sentido norte sul passando pelo leste.

Além disso, seguem os conceitos de Roberto Lamberts (2016), que orienta ajustar as aberturas em fachadas para essa micro zona bioclimática, de forma que essa ventilação não seja direta nas abertura e que não tenham dimensões avantajadas. Em contrapartida, a abertura será tradada de forma isolada no decorrer deste trabalho, pois o aproveitamento da ventilação natural na edificação trata-se de uma solução que só pode ser adotada em fase de projeto por meio do estudo dos fenômenos naturais, que proporcionam influência térmica na edificação. Essa é uma recomendação do Ministério das Cidades (2004), especificamente, que os municípios requalifiquem os projetos dessa tipologia para atender suas próprias características, que no caso especifico, trata-se da microrregião bioclimática onde a cidade de Cajazeiras-PB encontra-se inserida.

De acordo com o exposto, essa proposta teve o cuidado de tratar todas as unidades de modo que os recursos naturais propiciem o condicionamento térmico adequado na edificação. Além disso, que chegue de forma proporcional em todas as unidades, bem como a formatação do lote, que tem função estratégica, pois o dimensionamento de um lote quadrado e não retângulo possibilita o distanciamento entre as edificações, favorecendo assim, para arborização de forma mais eficaz.

Nesse sentido, não seria tecnicamente viável locar uma árvore de médio porte próximo às paredes da casa e da murada, pois pode provocar problemas à edificação, além de obstruir a circulação. Dessa forma, a opção por formatar em lotes quadrados faz parte do conjunto de estratégias adotadas para elaboração dessa proposta. 
Os elementos de sombreamento adotados para essa proposta estão dispostos de duas formas, elementos naturais e procedimentos construtivos, que tendem a melhorar as condições térmicas no interior da edificação. Essas estratégias adotadas consistem na formatação de beirais e locação de vegetação em pontos específicos, com intuito de requalificar a transição da ventilação do exterior para interior da edificação. Apesar de as soluções adotadas serem bastante simples, surtem efeito, que agregados a outras soluções tendem a melhorar o condicionamento térmico na edificação.

IMAGEM 4: VISTA DE TOPO.

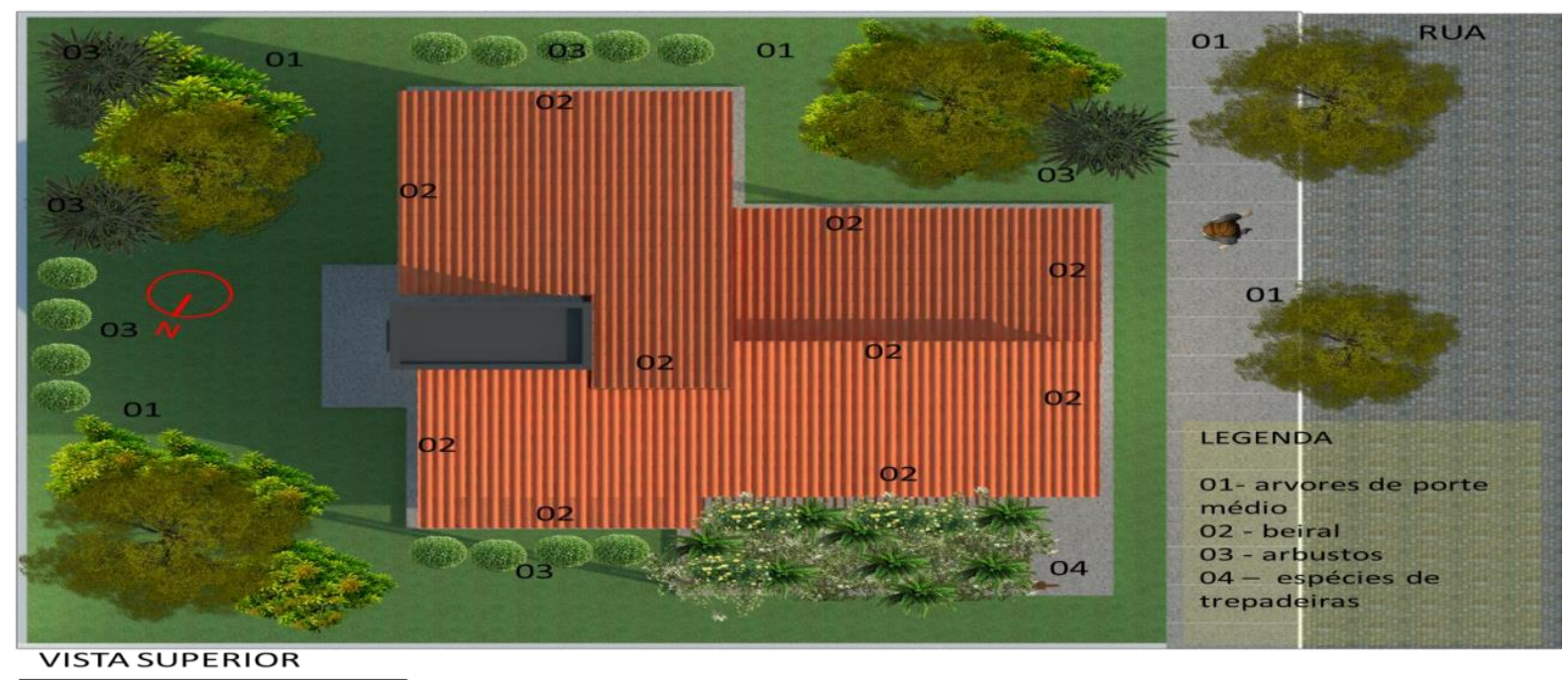

Fonte: Acervo do autor (2019).

Diante da observação acima, é possível perceber a locação da vegetação que auxiliará no melhoramento do ar que entrará na edificação. Ademais, minimizará a isolação nas fachadas e aumentará as áreas de sombreamentos. As duas árvores de médio porte locadas após a calçada são de uso obrigatório, já que a lei oㅡ 2.591 de 08 de novembro de 2016, no seu artigo $2^{\circ}$, determina que na construção de uso residencial, seja obrigatório o plantio de uma muda de árvore para cada 07 metros de frente. Além disso, serão implantados vegetação de pequeno e médio porte.

Outro elemento de sombreamento são os beirais com largura mínima de 80 centímetros, que percorrerá todo o perímetro da edificação, sombreando as fachadas e protegendo as esquadrias da água de chuva, minimizando também, os 
raios solares na edificação. Esse elemento de sombreamento é composto de madeira e telha cerâmica, que estão especificados em plantas. Para complementar o entendimento da estratégia adotada.

\section{IMAGEM 5: VISTA FRONTAL.}

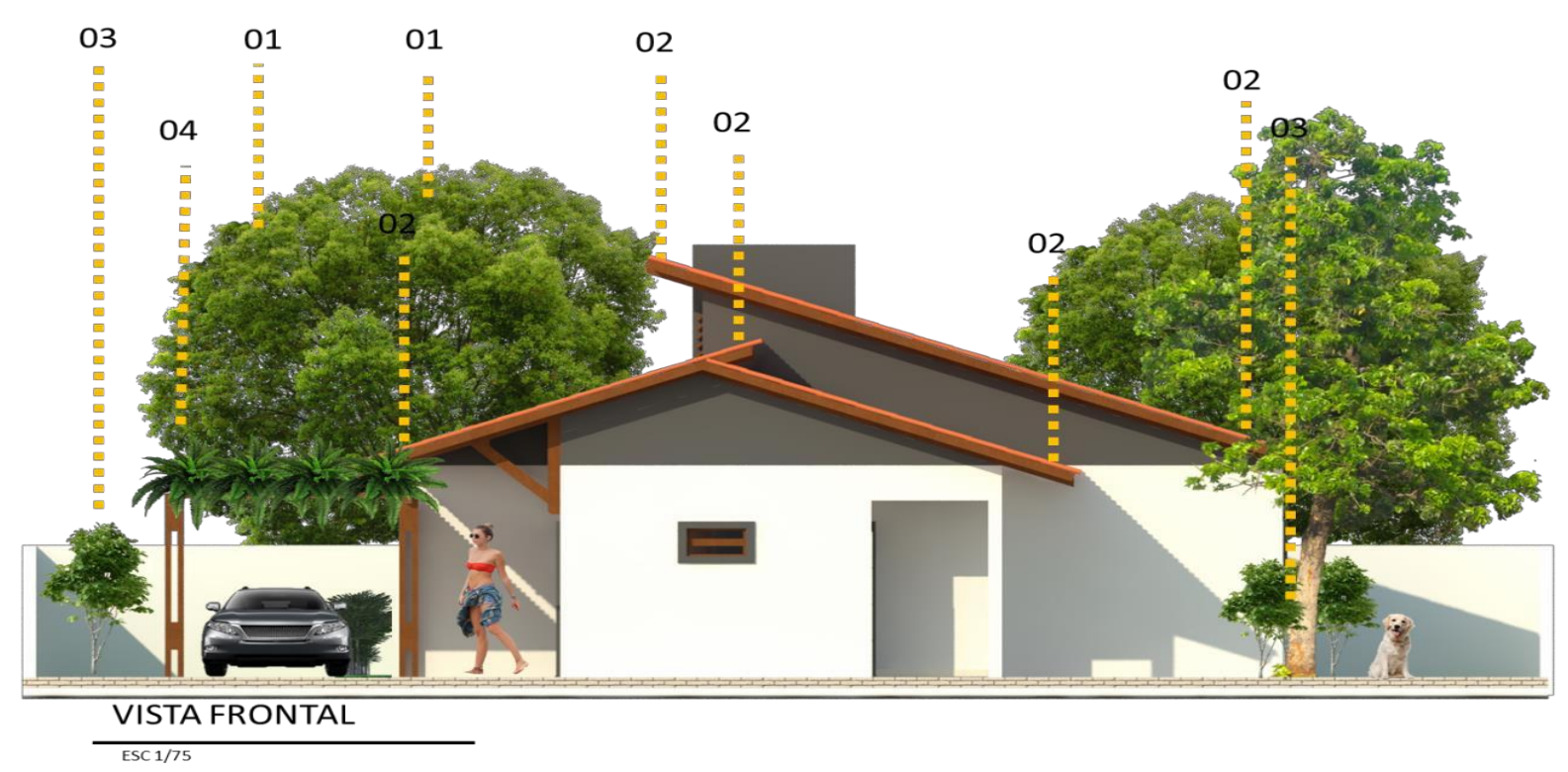

Fonte: Acervo do autor (2019).

$\mathrm{Na}$ configuração representativa da vista não estão inseridas todas as árvores dispostas. Nas vistas, é possível perceber como se comporta algumas dessas árvores, além de indicar o sombreamento do beiral. Por fim, tem-se a configuração de sombreamento nas fachadas de acordo com locação. Esse é um ponto bastante positivo, pois a flexibilidade do gabarito trás a possibilidade de atuar com as tipologias de fachadas e a inversão de fachadas, no qual a principal será a posterior e vice versa. Com essa possibilidade, é possível manter os ambientes de maior permanência locados de forma padrão independentemente da orientação da fachada principal.

As portas e janelas altas e baixas são locadas de forma condizentes com a ventilação natural, que foi disposta anteriormente por meios de estudos elaborados pelo LabEEE e que podem ser aplicados a esse projeto específico para microrregião de clima semiárido. As portas e janelas estão subdivididas com elementos fixos e 
outros que podem abrir totalmente ou parcialmente, o que possibilita o controle da quantidade de luz e vento que entra na edificação.

O material utilizado para fabricação desses elementos de grande importância no condicionamento térmico será a madeira com uma pequena fração de vidro, pois haverá momentos que se deseje permanecer com porta ou janelas fechadas e ainda assim, o interior do ambiente será iluminado de forma natural, e acima de tudo, para que se evite o acionamento de fonte de iluminação elétrica durante o dia, como mostra a análise de esquadrias seguinte:

A cobertura tem função de atenuar a carga térmica que chegará ao interior da edificação. A composição utilizada será a madeira cerrada com cobrimento de telha cerâmica canal, utilizando uma inclinação média de $35 \%$ em todas as águas, e inicia-se para os ambientes da sala, cozinha e área de serviço com um pé direito de 2,80 metros de altura. Já para os dormitórios, a coberta terá um pé direito de 3.35 metros de altura, melhorando ainda o condicionamento da temperatura ambiente.

Após descrever algumas características de como se comportará a cobertura dessa proposta, fez-se necessário fazer um comparativo entre coberturas com materiais distintos, no qual cada composição tem suas características próprias. Porém, para o emprego dessa proposta, deve-se compatibilizar a melhor solução com o menor custo, possibilitando a viabilidade técnica e financeira para o projeto proposto.

IMAGEM 6: COMPOSIÇÃO DE ALVENARIA 05.

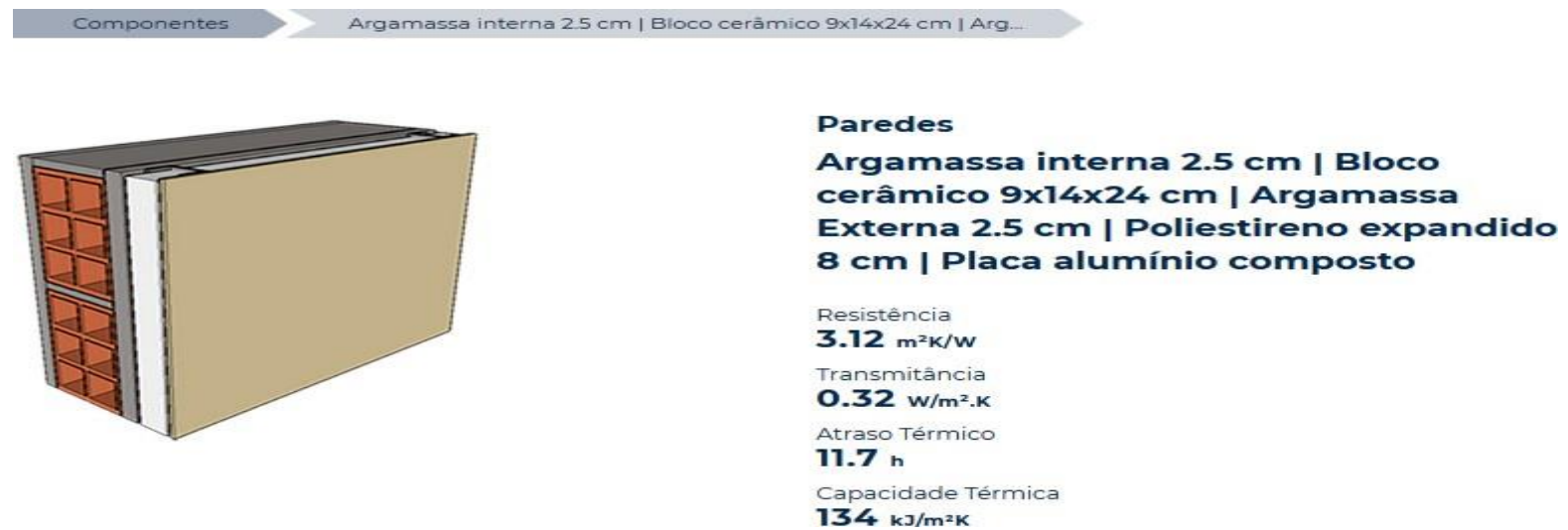

Fonte: Adaptado de Labeee (2019). 
Os elementos que compõem a alvenaria da imagem 5 são mais adequados para o melhoramento térmico em edificações, porém pelos mesmos critérios adotados na caracterização do elemento de cobertura, não é possível especificar essa formatação para alvenaria. Pois, também se trata de materiais que não condizem com os critérios de orçamento dessa proposta.

A estrutura para esse anteprojeto será de acordo com os princípios da NBR 6118 (2014), que dispõem sobre projeto de estrutura de concreto, que traz os critérios mínimos para o pré-dimensionamento. Dessa forma, todo pilar não poderá ter menos do que $14 \mathrm{~cm}$ de largura, e a área de sua seção não seja inferior a 360 $\mathrm{cm}^{2}$. De acordo com esses parâmetros iniciais, todas as unidades terão as demais configurações do pórtico estrutural.

Sapatas com base quadrada não inferior a $60 \mathrm{~cm}$, que receberão as vigas do baldrame. Essa composição de estrutura será nivelada na altura do piso acabado, em que todas as vigas do baldrame serão devidamente impermeabilizadas. Vale lembrar que as vigas dos baldrames geralmente são os elementos que dividem a etapa de fundação da etapa sequente, a supraestrutura, porém as vigas dos baldrames podem vir acima do nível do solo ou não. A partir do baldrame, iniciam-se as alvenarias e os pilares que darão a continuidade as sapatas.

No decorrer da etapa alvenaria, são inseridos outros elementos estruturais que são as vergas e contravergas utilizadas nas aberturas de portas e janelas. Logo, quando a alvenaria estiver toda em altura de pé direito, lança-se as vigas superiores, e por fim, as lajes da caixa d'água, finalizando o sistema de estrutura da edificação. Para melhor compreensão, a imagem 6 apresenta o pórtico da estrutura. 
IMAGEM 6: SISTEMA ESTRUTURAL EM CONCRETO ARMADO.
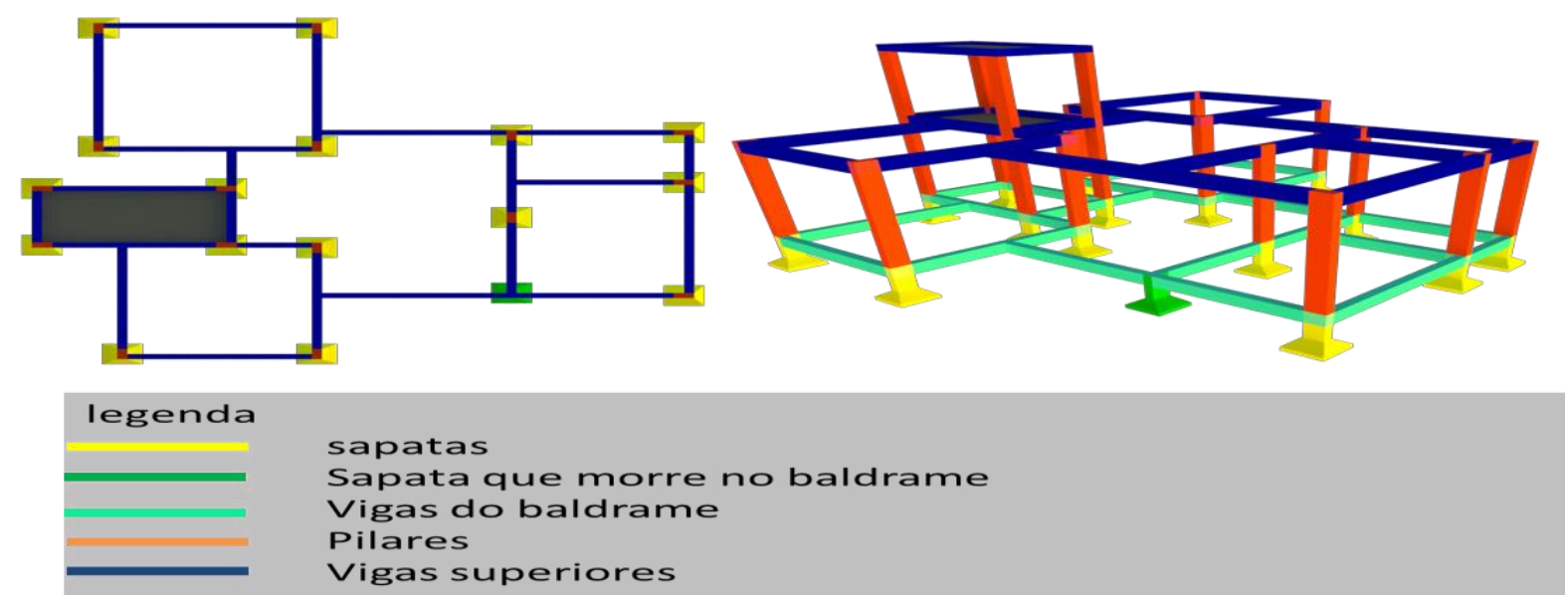

Fonte: Acervo do autor (2019).

Como visto na imagem 6 , percebe-se a compatibilização da estrutura com o layout proposto e que há uma sapata morrendo na viga do baldrame. O pórtico apresentado trás os pilares apenas até o nível do pé direito na viga superior, mas sabe-se que existem pilares que sobem para compor as empenas. A estrutura está pré-dimensionada segundo os princípios da normativa citada anteriormente, entretanto, pode sofrer alterações mínimas para este caso específico. Essa variação poderá acontecer no momento de lançamento das cargas, contudo percebe-se que independente da seção final das vigas e pilares, a estrutura não será aparente, pois a alvenaria esta compatível com esse dimensionamento da estrutura.

Para complementar o sistema estrutural adiciona-se às vergas e contravergas, aplicando dentro do sistema de estrutura adotado. Esses elementos independem do pórtico já exposto anteriormente, e podem ser tratadas de forma isolada sendo compatibilizados com as aberturas de portas e janelas constantes no projeto.

Entende-se que, com a implantação de 252 unidades em uma área de 324. 014,60 $\mathrm{m}^{2}$, uma grande área será pavimentada de ruas e calçadas. Nesse sentido, está sendo disponibilizado uma média de $50 \%$ das áreas dos lotes sem pavimentação, para contribuir com absorção das águas pluviais e acima de tudo, evitar enxurradas que possam prejudicar o conjunto e até mesmo outras áreas 
adjacentes. Os índices de ocupação individual podem ser encontrados no quadro de uso e ocupação nas plantas constantes nesse trabalho.

A paisagem dessa área ociosa que está sendo utilizada para implantação das unidades, passará pelo processo de urbanização e serão integradas as áreas já consolidadas, porém terá sua própria identidade que atenderá diversos critérios específicos que fazem parte das soluções arquitetônicas adotadas para essa implantação. O distanciamento mínimo de $4 \mathrm{~m}$ entre as unidades possibilitará uma arborização em todas as fachadas, além da arborização imposta pela lei municipal já citada anteriormente, no qual para 252 unidades habitacionais terá que ser implantadas 504 árvores obrigatórias. Entende-se que a composição da paisagem dessa área será extremamente verde, formando um pequeno oásis em uma região semiárida, conforme pode ser observado nas imagens seguintes:

IMAGEM 7: CONFIGURAÇÃO DA PAISAGEM E PLANTIO DE ARVORES.

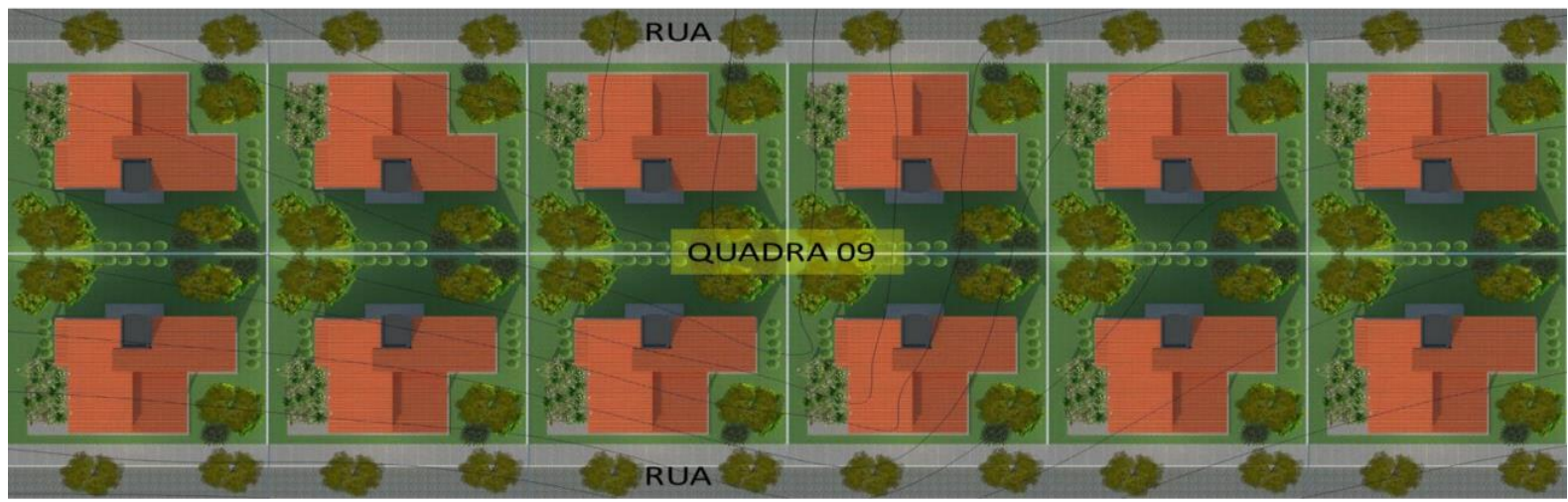

Fonte: Acervo do autor (2019) 
IMAGEM 8: VISTA DA FRONTAL DA QUADRA 09.

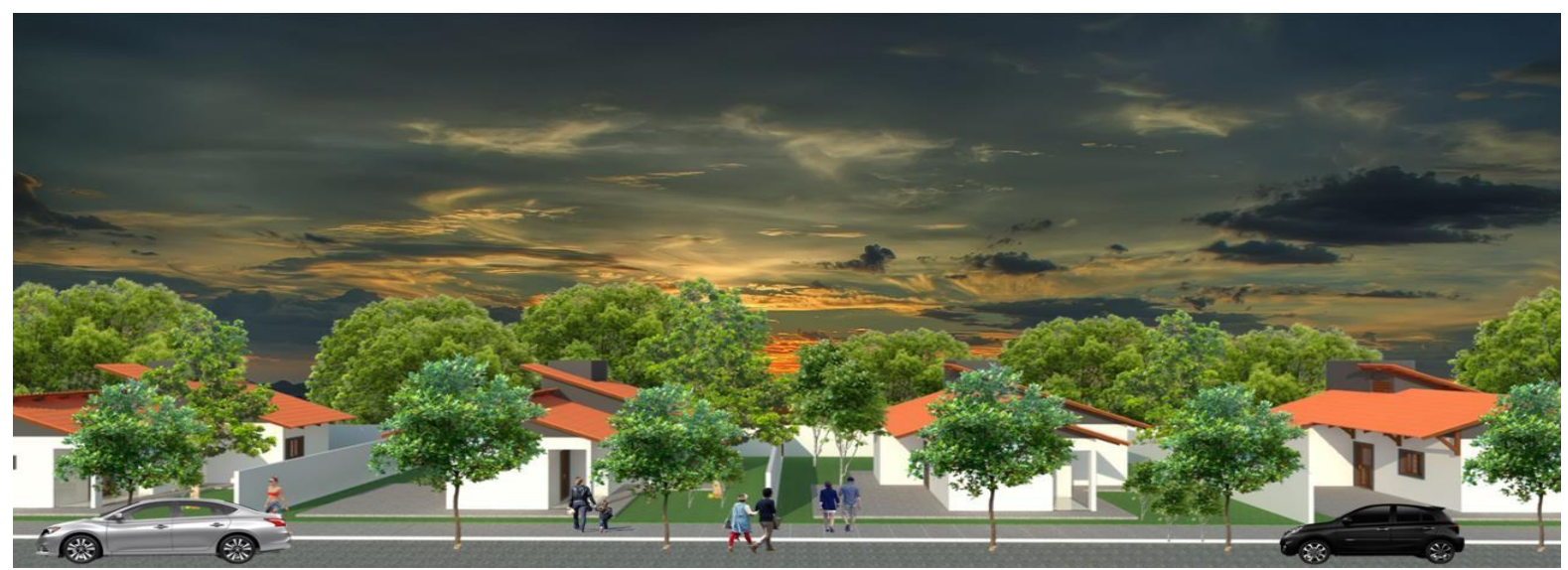

Fonte: Acervo do autor (2019).

A representação acima se trata da quadra 09 da área de implantação que representa toda área. Isso possibilita compreender o quanto será arborizado e permeável, além de expor a configuração paisagística da intervenção urbana através das novas habitações.

\section{CONCLUSÃO}

O desenvolvimento dessa proposta de anteprojeto para implantação e construção de um conjunto habitacional de interesse social com unidades térreas buscou soluções possíveis e aplicáveis, com a finalidade de desenvolver uma proposta compatível tecnicamente e financeiramente com essa tipologia de habitação. Essa proposta de anteprojeto fez uso de elementos teóricos e soluções simples e acessíveis ao padrão proposto. Ressaltou-se ainda, a possibilidade de propor soluções arquitetônicas que podem ser utilizadas em edificações nessa micro zona bioclimática, que refere-se ao clima semiárido.

No entanto, é importante frisar que apesar de tratar-se de um anteprojeto, os estudos e levantamentos, bem como todos os desenhos técnicos desenvolvidos até esta fase do trabalho podem ser finalizados sem prejuízos ao montante já desenvolvido. Partindo desse entendimento e considerando que um anteprojeto não 
retrata um trabalho inacabado, mas sim um conjunto de medidas aplicáveis à espera de detalhamentos que vão auxiliar a execução in loco, é importante entender que se atinge o objetivo quando se consegue retratar todas as informações subjetivas da pesquisa feita.

Por fim, é possível avaliar de forma positiva as estratégias adotadas, pois os principais elementos construtivos como estrutura, alvenaria e coberta foram analisados de forma específica, para que a composição da unidade possa aproveitar os elementos naturais, pois são os principais elementos passivos de melhoramento térmico. Contudo, o resultado dessa proposta é viável tecnicamente, podendo ser utilizada na cidade de Cajazeiras-PB ou em qualquer outra cidade dessa mesma micro zona bioclimática.

\section{REFERÊNCIAS BIBLIOGRÁFICAS}

ASSOCIAÇÃO BRASILEIRA DE NORMAS TÉCNICAS. NBR 6492: Representação de projetos de arquitetura. Rio de Janeiro, 1994.

Janeiro: 2003.

NBR 15220: Desempenho térmico de edificações. Rio de

de Janeiro: 2003.

NBR 15575-5: Edificações habitacionais - Desempenho. Rio

NBR 15215-3: lluminação natural. Rio de Janeiro: 2005.

BRASIL. Lei $n^{\circ} 6.766$ de 19 de dezembro de 1979. Dispõe sobre o Parcelamento do Solo Urbano e dá outras Providências. Diário Oficial [da] República Federativa do Brasil, Poder Executivo, Brasília, DF, 20 dez. 1979.

. Lei $n^{\circ} 11.977$ de 07 de julho de 2009. Dispõe sobre o Programa Minha Casa, Minha Vida - PMCMV e a regularização fundiária de assentamentos localizados em áreas urbanas; altera o Decreto-Lei no 3.365, de 21 de junho de 1941, as Leis nos 4.380, de 21 de agosto de 1964, 6.015, de 31 de dezembro de 1973, 8.036, de 11 de maio de 1990, e 10.257, de 10 de julho de 2001, e a Medida Provisória oㅡ 2.197-43, de 24 de agosto de 2001; e dá outras providências. Diário Oficial [da] República Federativa do Brasil, Poder Executivo, Brasília, DF, 08 jul. 2009.

BONDUKI, N. G. Origens da habitação social no Brasil. Análise social, Análise Social, v. XXIX, n.127, p. 711-732, 1994.

DA SILVA, P. C. G. et al. Semiárido brasileiro: pesquisa, desenvolvimento e inovação. Petrolina: Embrapa Semiárido, 2010.

FROTA, A. B.; SCHIFFER, S. R. Manual de conforto térmico. São Paulo: Studio Nobel, 2001. 
INNES, M. Iluminação do design de interiores. São Paulo: Gustavo Gili, 2014.

LAMBERTS, R. et al. Eficiência energética na arquitetura. São Paulo: PW Editores PROCEL, 1998.

LE DANTEC, C. A.; DO, E. Y. The mechanisms of value transfer in design meetings. Design Studies, v. 30, n. 2, p. 119-137, 2009.

NEUFERT, E.; KISTER, J. Arte de projetar em arquitetura. São Paulo: Gustavo Gili, 2014.

PALERMO, C. et al. Habitação Social: uma visão projetual. Colóquio de Pesquisas em Habitação, v. 4, 2007. 